\title{
THERMAL STABILITY OF PREPARED CHICKEN FEET GELATINE GEL IN COMPARISON WITH COMMERCIAL GELATINES
}

\author{
Petr Mrázek, Robert Gál, Pavel Mokrejš, Ondřej Krejčí, Jana Orsavová
}

\begin{abstract}
Gelatine is, due to its functional properties, currently widely used not only in the food industry (in the production of confectionery, dairy products, canned food) but also in pharmacy (soft and hard capsules) and cosmetics (creams, lotions) where it applies its ability to form thermoreversible gel stronger than most other gelling agents. What is more, it provides further excellent properties including emulsifying, foaming, stabilizing, film-forming, water and fat binding, texturizing, thickening, and adhesive attributes which makes it a very important hydrocolloid. Gelatine is obtained from the raw material of animal tissues containing collagen, usually mammalian skin or bones. For religious reasons in some countries, pork or bovine gelatine must be replaced by an alternative form, such as poultry or fish gelatine. The quality of gelatine is assessed mostly by the strength of gelatine gel which strongly depends on ambient temperature or humidity. Extraction conditions may also significantly affect the quality of gelatine. This study examined possible changes in the strength of gelatine gels prepared from laboratory-produced chicken feet gelatine and compared them with commercially available pork and beef gelatines at temperatures of 23,29 , and $35{ }^{\circ} \mathrm{C}$ at 60 and $80 \%$ humidity. While at $23{ }^{\circ} \mathrm{C}$ thermal stability of prepared chicken gelatine was monitored higher than in commercial gelatines, experiments at 29 and $35^{\circ} \mathrm{C}$ provided equivalent results for chicken and commercial gelatines. Therefore, prepared chicken gelatine offers a significant potential to become an alternative to traditional gelatines. The information about gelatine gels thermal stability is of great importance for applications not only in the food; but also in the pharmaceutical industry.
\end{abstract}

Keywords: chicken feet; collagen; gelatine; gel strength; poultry by-products; thermal stability

\section{INTRODUCTION}

Gelatine is a multifunctional biopolymer acknowledged as a functional food due to its positive effects on human health (Jellouli et al., 2011). The application of gelatine dates back to 4000 B.C. when Egyptians used glue based on gelatine to connect parts of furniture (Koepff, 1985). At the end of the seventeenth century, commercial production of gelatine commenced. More than a hundred years later, the production process significantly enhanced and high molecular weight gelatine was produced. Thus, consequently, the high quality of gelatine gels was obtained (Bogue, 1922; Smith, 1929). At present, annual gelatine production comprises approximately 583.400 tonnes per year worldwide (Grand View Research, 2020).

Gelatine is acquired by thermal denaturation or partial hydrolysis of materials containing collagen which is (Mohtar et al., 2010) a fiber-forming protein important for maintaining the structure of animal tissues (Li et al., 2009). It is the most widespread protein in mammals accounting for up to 30\% of all proteins (Perez-Tamayo, 1978). Scientific literature states that 29 different types of collagen have been currently identified (Silvipriya et al., 2015). Collagen (type I) is an insoluble fibrous structural protein abundant (about 25\%) in animal tissues, such as skins, bones, tendons, ligaments, and cornea (Maroušek et al., 2015; Krishnamoorthi et al., 2017). Collagen possesses significant properties including high tensile strength, low antigenicity, and good biocompatibility (Subhan et al., 2017). The collagen molecule is comprised of three polypeptide chains that form a helical structure. Chains conformation is changed during gelatine gelation and a three-dimensional network structure similar to the natural arrangement of collagen is created (Bigi et al., 2004). Gelatine has a lower molecular weight than native collagen because it is composed of a mixture of polypeptide segments with a molecular weight in the range of $16-150 \mathrm{kDa}$ (Asghar and Henrickson, 1982).

Physical properties of gelatine, such as gel-forming ability, water holding capacity, fat binding capacity, or emulsifying and foaming properties, are of great significance in applications particularly in the food industry within many products, such as marshmallows, jellies or gummy bears. Thermal stability of gelatine at temperatures between 25 and $30{ }^{\circ} \mathrm{C}$ is also principal in 
gelatine desserts or in applications of gelatine in combination with other hydrocolloids including agar-agar gels in fruit gummies where it is essential to maintain required clarity or textural properties (Schrieber and Gareis, 2007). According to the analysis by Grand View Research (2020), gelatine is applied most as a stabilizer (238.000 tonnes), thickener (186.000 tonnes) and gelling agent (147.000 tonnes) which emphasizes the fact that thermal stability of gelatine gels is one of the most significant required gelatine attributes. These functional properties primarily affect the texture and appearance of the final products ( $\mathbf{L i}$ et al., 2009). Gelatine's ability to retain molecules of water is advantageously utilized also in cosmetic formulations (Deyl et al., 2003). Considering these valuable characteristics, gelatine is also extensively used in biomedicine and pharmaceutical industry (Bae et al., 2008). Gelatine has antimicrobial or antioxidant properties providing the ability to act as an antihypertensive agent via angiotensin inhibition (ACE) (Gómez-Guillén et al., 2011). Several studies have revealed that gelatine and especially gelatine hydrolysates exhibit regenerative effects on the human skeleton and spinal cord systems (Schrieber and Gareis, 2007).

One of the most important quality indicators is gelatine gel strength (Bloom value). Reflecting its value, gelatine is classified into low gel strength gelatine ( $\leq 150$ Bloom), medium gel strength gelatine $(150-220$ Bloom $)$, and high gel strength gelatine $(220$ - 300 Bloom) (Johnston-Bank, 1983). Gelatine gel strength may depend on several different factors, such as the age, species, and gender of the animal used as raw material, technological conditions of gelatine preparation, including pre-treatment method, extract temperature and time, and the ambient conditions $\mathrm{pH}$, temperature and humidity.

The thermal stability of different types of gelatines has been thoroughly examined. Losso and Ogawa (2013) determined the thermal stability of chicken keel bone collagen. Pati et al. (2010) isolated and characterized fish scale collagen of higher thermal stability. In both studies, thermal stability was established using denaturation temperature. Michon et al. (1997) investigated the influence of thermal history on the stability of gelatine gels using the DSC method. Rodriguez-Rodriguez et al. (2019) studied the development of thermal stability of gelatine/chitosan/PVA hydrogels. To determine the thermal stability of gelatines, the DSC method and rheological testing were applied. Canpanean et al. (2013) examined the enhanced thermal stability of gelatine coated gold nanorods in water solution. Thermal stability was established using UV-visible spectrophotometry and TEM microscopy. Masutani et al. (2014) monitored increased thermal stability of gelatine films by UV-induced crosslinking with glucose applying the DSC method, SEM microscopy, and UV-visible spectrophotometry. Crosslinking is one of the three methods to enhance the thermal stability of gelatines. Rodriguez-Castellanos et al. (2014) examined nanomechanical properties and thermal stability of recycled cellulose reinforced by a starch-gelatin polymer composite using SEM microscopy and TGA analysis. However, very little data deals with the thermal stability of gelatine gel strength which is a key parameter to evaluate gelatine quality in food, such as confections, aspics, dairy, and meat products. Therefore, this study focuses on the changes in gel strength of products containing gelatine gel during the storage at different temperatures.

\section{THE AIMS OF THIS STUDY}

The study aims to continue the research of biotechnological processing of poultry by-products into gelatine (Mrázek et al., 2019) and to prepare chicken feet gelatine (CFG), beef, and pork gelatine gels. Furthermore, to monitor an impact of temperature and humidity on CFG gels during the storage at different temperatures of 23, 29 and $35^{\circ} \mathrm{C}$ as a simulation of standard storage conditions suitable for food products containing gelatine, and simultaneously, as a simulation of storage conditions in summers in the moderate climate zone and subtropical or tropical areas. It also provides tests at an increased relative humidity (60 and 80\%) since gelatine gels are commonly stored in cooling facilities with humidity often up to $80 \%$. It compares CFG with commercially available pork and beef gelatine.

\section{Scientific hypothesis}

The research has tested the hypothesis that the thermal stability of gelatine gels decreases with rising temperature and humidity.

\section{MATERIAL AND METHODOLOGY}

\section{Appliances, tools, and chemicals}

Stevens LFRA Texture Analyser for measuring gelatine gel strength (Leonard Farnell and Co Ltd., England), P 98 meat mincer (Brather, Spain), Memmert ULP 400 drying device (Memmert GmbH + Co. KG, Germany), LT 43 shaker (Nedform, Czech Republic), Kern 440 - 47 electronic scale, Kern 770 electronic analytical scale (Kern, Germany), A 10 labortechnik analytical mill (IKAWerke, Germany), ULP 400 drying oven (Memmert $\mathrm{GmbH}+\mathrm{Co}$. KG, Germany), SLR heating board (Schott Gerate GmbH, Germany), Whatman No. 1 paper (Sigma Aldrich, UK), a metal filter sieve with the size of pores 1 and $2 \mathrm{~mm}$ (Labor-komplet, Czech Republic). Chemicals: $\mathrm{NaCl}, \mathrm{NaOH}$, petroleum ether, ethanol, and chloroform (Verkon, Czech Republic); all chemicals were of analytical grade. Proteolytic enzyme Polarzyme 6.0 T - serine endoprotease manufactured by fermentation of microorganisms that are not present in the final product (Novozymes, Denmark) with the declared enzyme activity of $6 \mathrm{KPU}$ per $\mathrm{g}$ (kilo protease unit per g). Commercial mammalian gelatines: pork gelatines with the gel strength of 212 and 288 Bloom, beef gelatines with the gel strength of 266 and 273 Bloom.

\section{Preparation and measurement of chicken feet gelatine (CFG) gels}

Chicken feet were purchased in Raciola Uherský Brod, Czech Republic, and processed to chicken feet gelatine according to the method described by Mokrejš et al. (2019). Two types of pork gelatines and two types of beef gelatines were purchased as well and used for the comparison. 
Table 1 Initial Bloom values of chicken feet, beef and pork gelatine gels.

\begin{tabular}{cccccc}
\hline Type of gelatine & Beef266 & Beef273 & Pork212 & Pork288 & CFG240 \\
\hline Bloom value \pm SD & $266 \pm 3$ & $273 \pm 2$ & $212 \pm 2$ & $288 \pm 4$ & $240 \pm 3$ \\
\hline
\end{tabular}

Note: CFG denote chicken feet gelatine; Beef266 and Beef273 are beef gelatines with Bloom values of 266 and 273;

Pork212 and pork288 are pork gelatines with Bloom values of 212 and 288.

Gelatine gels were prepared following GMIA - Standard Testing Methods for Edible Gelatin (2019) so that $7.5 \mathrm{~g}$ of gelatine was mixed with $105 \mathrm{~mL}$ distilled water and placed into a standardized bloom jar with a volume of $150 \mathrm{~mL}$ and dimensions as follows: overall height of 85 $\mathrm{mm}$, inside diameter of $59 \mathrm{~mm}$, outside diameter of 66 $\mathrm{mm}$, neck inside diameter of $41 \mathrm{~mm}$, and a shoulder height of $65 \mathrm{~mm}$. The mixture was allowed to swell at room temperature for $1-3 \mathrm{~h}$. Afterward, the bloom jar (Figure 1) was heated in a water bath at $65^{\circ} \mathrm{C}$ to prepare a gelatine solution which was cooled at room temperature and maintained in a cooling box for $16-18 \mathrm{~h}$ to form gelatine gel. Gel strength (or Bloom value) was measured by Stevens LFRA Texture Analyser (Leonard Farnell and Co Ltd., England, Figure 1). Gelatine gel strength is defined as a force (weight in $\mathrm{g}$ ) required to depress a measuring probe by specific penetration to a definite area of the gelatine surface to a particular distance.
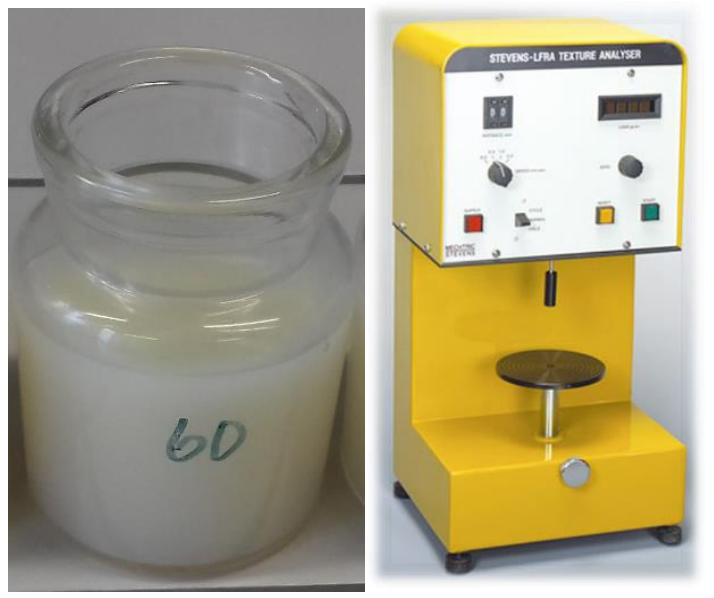

Figure 1 Prepared chicken feet gelatine gels (left) Stevens LFRA Texture Analyser (right).

\section{Determination of thermal stability of gelatine gels}

Studies examining gelatine gels thermal stability mostly used methods of thermal analysis (DSC), rheological testing, or determination of activating energy. Considering a wide range of applications of gelatines in the food industry assessing the quality of gelatines based on their gels strength, this study has employed a method of measuring gel strength according to GMIA - Standard Testing Methods for Edible Gelatin (2019). It has monitored a decline of gel strength in time which is in contrast with other studies that have not considered testing of gelatines on a long-term time scale. The thermal stability of gelatine gels was expressed as a percentage change (decline) of gelatine gel strength during the time period of 5 days. Gelatine gel strength was measured every hour within the first 8 hours of the experiment, and then after 16, 23, 87, 93, 111, and 120 hours. Experiments were performed at three different temperatures of 23, 29, and $35{ }^{\circ} \mathrm{C}$ with the relative humidity of 60 and $80 \%$. In total, six series of experiments were performed in which 30 gelatine samples were analysed.

\section{Statistic analysis}

1 -sample and 2-sample standard deviation tests on the significance level of $p=0.05$ were applied to all results using Minitab 18 statistical software for Windows (Minitab, Ltd., USA). All analyses were performed in triplicate and arithmetic means and standard deviations were calculated.

\section{RESULTS AND DISCUSSION}

\section{The gel strength of prepared chicken feet and commercial pork and beef gelatine gels}

Table 1 displays initial Bloom values of commercial mammal and prepared chicken feet gelatines ranging in all samples between 220 and 300 which means all tested gelatines showed a significant gel strength (JohnstonBank, 1983). The highest gel strength was recorded in Pork288 and the lowest in Pork212. The gel strength of prepared chicken feet gelatine was 240 Bloom. Gel strength of commercial pork and beef gelatine gels ranging from 100 to 300 Bloom, whereas $200-250$ Bloom is most preferred (Holzer, 1996). Several studies discussing the preparation and testing of the strength of chicken feet gelatine gels were published. Taufik et al. (2010) examined the effect of age and extraction temperature on characteristics of chicken feet skin gelatine and reported Bloom values from 112 to 125 which is significantly lower than the values of chicken feet gelatine prepared in this study. Rahman and Jamalulail (2012) performed extractions of chicken feet gelatine, inspected its physicochemical characteristics and sensory quality, and recorded the value of 264 Bloom which is slightly higher than the value of chicken feet gelatine established in this study. Widyasari and Rawdkuen (2014) described gelatine obtained from chicken feet by acid and ultrasound-assisted extraction and reported Bloom values of 185 and 79 which is less than this study provided. Chakka et al. (2016) extracted chicken feet gelatine using food-grade acids and monitored the gel strength in the range from 119 to 204 Bloom which is less than it was recorded in this study. Almeida and Lannes (2013) extracted gelatine from chicken feet and characterized its physicochemical properties. They confirmed the gel strength of 295 Bloom which is more than it was measured in this study. Sompie and Triasih (2018) reported very low gel strength of chicken leg skin gelatine (78 Bloom). On the contrary, in the case of gelatine extracted from residues after mechanical processing of poultry meat, very high Bloom values were recorded: 309-318 Bloom (Fonkwe and Singh, 1997) and 374-380 Bloom (Rafieian et al., 2013) and (Rafieian et al., 2015). High Bloom values have also been reported for poultry gelatine by other researchers: 294 Bloom (Almeida, Calarge and 
Santana, 2013), 338 Bloom (Du, et al., 2014) and 355 Bloom (Ee et al., 2019) and (Sarbon et al., 2013). Such differences in results may stem from different extraction conditions, particularly time and temperature, as well as from the applied pre-treatment method. The age and gender of the animal could also affect the quality of prepared gelatines.

\section{Determination of thermal stability of prepared chicken feet and commercial pork and beef gelatine gels}

The results of determination of the thermal stability of chicken feet, beef, and pork gelatine gels tested at the temperatures of 23,29 , and $35^{\circ} \mathrm{C}$ and relative humidity of 60 and $80 \%$ are shown in Tables $2-7$. Initial Bloom values of gelatines are expressed as $100 \%$. Changes in gelatine gel strength (declines) are expressed as Bloom index in $\%$.

Table 2 shows the results of the thermal stability of chicken feet, pork, and beef gelatines at a temperature of $23{ }^{\circ} \mathrm{C}$ and humidity of $60 \%$. Gel strength gradually decreased as expected. After one hour of measurement, the slightest decline was recorded in CFG240 and the highest in Beef273. A drop of gel strength in other types of gelatines was approximately $25 \%$; differences were not statistically significant $(p>0.05)$. Similar trends were observed also in the following measurements with declines of gel strength between 30 and $65 \%$. The smallest decrease of gel strength was recorded in chicken feet gelatine while the most significant drop was determined in Beef273 $(3-5 \mathrm{~h}$ of measurement) followed by Pork212 (87 - $120 \mathrm{~h}$ of measurement). Within the last two measurements (after 111 and $120 \mathrm{~h}$ ), no further changes in gel strength were established. The deepest decline in gel strength in the final measurement was monitored in Beef266 (more than 90\%) while the smallest drop was identified in prepared gelatine CFG240 (approximately 75\%); this gelatine showed this trend for the whole testing period. The reduction of gel strength in other types of gelatines was approximately $85 \%$ with statistically insignificant differences $(p>0.05)$.

Table 3 summarizes the measurements of the thermal stability of chicken feet, pork and beef gelatines at the temperature of $23{ }^{\circ} \mathrm{C}$ and humidity of $80 \%$. Prepared chicken feet gelatine CFG240 provided values with statistically insignificant differences $(p>0.05)$ recorded at both levels of humidity -60 and $80 \%$.

Table 2 Thermal stability of chicken feet, beef and pork gelatines at $23{ }^{\circ} \mathrm{C}$ and relative humidity of $60 \%$.

\begin{tabular}{cccccc}
\hline Temperature of $\mathbf{2 3}^{\circ} \mathbf{C}$; relative humidity of $\mathbf{6 0} \%$ & \multicolumn{4}{c}{ Type of gelatine/Bloom index (\%) } \\
\hline Time of measurement $\mathbf{( h )}$ & Beef266 & Beef273 & Pork212 & Pork288 & CFG240 \\
\hline 0 & 100 & 100 & 100 & 100 & 100 \\
1 & 77 & 61 & 76 & 75 & 87 \\
2 & 50 & 35 & 47 & 50 & 68 \\
3 & 35 & 27 & 33 & 37 & 57 \\
4 & 28 & 26 & 24 & 29 & 51 \\
5 & 24 & 25 & 21 & 26 & 49 \\
6 & 23 & 24 & 20 & 25 & 45 \\
7 & 22 & 23 & 19 & 24 & 45 \\
8 & 22 & 22 & 18 & 23 & 44 \\
16 & 21 & 21 & 18 & 20 & 40 \\
23 & 20 & 20 & 17 & 18 & 39 \\
87 & 8 & 14 & 15 & 16 & 28 \\
93 & 8 & 13 & 14 & 16 & 24 \\
11 & 8 & 13 & 14 & 15 & 23 \\
\hline
\end{tabular}

Table 3 Thermal stability of chicken feet, beef and pork gelatines at $23{ }^{\circ} \mathrm{C}$ and relative humidity of $80 \%$.

\begin{tabular}{|c|c|c|c|c|c|}
\hline \multirow{2}{*}{$\begin{array}{c}\text { Temperature of } 23{ }^{\circ} \mathrm{C} \text {; relative humidity of } 80 \% \\
\text { Time of measurement }(\mathrm{h})\end{array}$} & \multicolumn{5}{|c|}{ Type of gelatine/Bloom index (\%) } \\
\hline & Beef266 & Beef273 & Pork212 & Pork288 & CFG240 \\
\hline 0 & 100 & 100 & 100 & 100 & 100 \\
\hline 1 & 82 & 70 & 82 & 87 & 85 \\
\hline 2 & 58 & 46 & 56 & 62 & 67 \\
\hline 3 & 45 & 37 & 42 & 49 & 57 \\
\hline 4 & 37 & 32 & 34 & 41 & 50 \\
\hline 5 & 34 & 31 & 30 & 37 & 48 \\
\hline 6 & 32 & 31 & 25 & 35 & 46 \\
\hline 7 & 31 & 31 & 24 & 33 & 44 \\
\hline 8 & 30 & 30 & 24 & 32 & 43 \\
\hline 16 & 29 & 29 & 24 & 32 & 40 \\
\hline 23 & 29 & 24 & 24 & 32 & 38 \\
\hline 87 & 19 & 20 & 18 & 22 & 27 \\
\hline 93 & 19 & 20 & 18 & 22 & 25 \\
\hline 111 & 19 & 20 & 18 & 22 & 23 \\
\hline 120 & 19 & 20 & 18 & 22 & 23 \\
\hline
\end{tabular}


However, within commercial gelatines in the first 6 hours of measurement, higher declines of gelatine gel strength with statistically significant differences $(p<0.05)$ were recorded at the humidity of $80 \%$ than $60 \%$. In the following measurements, statistically significant $(p<0.05)$ smaller declines of commercial gelatine gel strength were recorded at the humidity of $80 \%$ than $60 \%$. After $1 \mathrm{~h}$ of measurement, the slightest drop of gelatine gel strength was identified in Pork288 and the most considerable in Beef273. In all the following measurement CFG240 showed the smallest decline. After two hours of testing, the fall of gelatine gel strength ranged from 33 to $64 \%$. The deepest decline in 2, 3, and $4 \mathrm{~h}$ of measurement were recorded in Beef273 whereas in further measurements the most significant decrease was determined in Pork212. Nevertheless, within the measurement in 111 and $120 \mathrm{~h}$, no further changes in gelatine gel strength were identified with the final declines of the strength of approximately $80 \%$. Prepared chicken feet gelatine performed either comparable or even better thermal stability at a humidity of 60 and $80 \%$ if compared with commercial beef and pork gelatine.

The results of the thermal stability of chicken feet, pork, and beef gelatines at the temperature of $29{ }^{\circ} \mathrm{C}$ and humidity of $60 \%$ are displayed in Table 4 . In contrast with the measurements at the temperature of $23{ }^{\circ} \mathrm{C}$ and humidity of $60 \%$, a significantly deeper $(p<0.05)$ decline of gel strength in all gelatines was monitored in 2-h measurement and further. After $1 \mathrm{~h}$, the smallest decrease was monitored in Beef266 and both pork gelatines, while in CFG240 and Beef273 the deepest reduction of gel strength was recorded. In further measurements, the smallest drop was identified in Beef266 and Pork288 (63\%), slightly deeper in Pork212 and CFG240 (65\%), and the most significant decline in Beef273 (72\%). After 3 and $4 \mathrm{~h}$ of measurement, the smallest decrease was recorded in Beef266, Pork288, and CFG240 and the deepest fall in Beef273 and Pork212. After 5, 6, 7, and $8 \mathrm{~h}$, gelatine CFG240 showed the slightest decline of approximately $90 \%$ while other types of gelatines performed slightly higher, yet statistically insignificant $(p>0.05)$ declines of gelatine gel strength. A similar trend was observed in further measurements and after $87 \mathrm{~h}$ of measurement, no gelatine showed a change in gel strength. The final decline of gel strength was almost $100 \%$.

Table 4 Thermal stability of chicken feet, beef and pork gelatines at $29^{\circ} \mathrm{C}$ and relative humidity of $60 \%$.

\begin{tabular}{|c|c|c|c|c|c|}
\hline Temperature of $29^{\circ} \mathrm{C}$; relative humidity of $60 \%$ & \multicolumn{5}{|c|}{ Type of gelatine/Bloom index (\%) } \\
\hline Time of measurement $(\mathrm{h})$ & Beef266 & Beef273 & Pork212 & Pork288 & CFG240 \\
\hline 0 & 100 & 100 & 100 & 100 & 100 \\
\hline 1 & 76 & 63 & 77 & 75 & 66 \\
\hline 2 & 37 & 28 & 33 & 37 & 33 \\
\hline 3 & 21 & 16 & 16 & 21 & 20 \\
\hline 4 & 14 & 12 & 11 & 14 & 15 \\
\hline 5 & 11 & 10 & 8 & 10 & 13 \\
\hline 6 & 9 & 9 & 7 & 9 & 11 \\
\hline 7 & 8 & 8 & 6 & 8 & 9 \\
\hline 8 & 7 & 7 & 5 & 6 & 7 \\
\hline 16 & 4 & 5 & 4 & 4 & 6 \\
\hline 23 & 4 & 4 & 3 & 4 & 5 \\
\hline 87 & 3 & 4 & 3 & 3 & 3 \\
\hline 93 & 3 & 4 & 3 & 3 & 3 \\
\hline 111 & 3 & 4 & 3 & 3 & 3 \\
\hline 120 & 3 & 4 & 3 & 3 & 3 \\
\hline
\end{tabular}

Table 5 Thermal stability of chicken feet, beef and pork gelatines at $29^{\circ} \mathrm{C}$ and relative humidity of $80 \%$.

\begin{tabular}{|c|c|c|c|c|c|}
\hline \multirow{2}{*}{$\begin{array}{c}\text { Temperature of } 29^{\circ} \mathrm{C} \text {; relative humidity of } 80 \% \\
\text { Time of measurement }(\mathrm{h})\end{array}$} & \multicolumn{5}{|c|}{ Type of gelatine/Bloom index (\%) } \\
\hline & Beef266 & Beef273 & Pork212 & Pork288 & CFG240 \\
\hline 0 & 100 & 100 & 100 & 100 & 100 \\
\hline 1 & 74 & 64 & 71 & 69 & 64 \\
\hline 2 & 30 & 22 & 26 & 31 & 33 \\
\hline 3 & 14 & 12 & 11 & 14 & 19 \\
\hline 4 & 8 & 8 & 6 & 8 & 15 \\
\hline 5 & 6 & 7 & 4 & 6 & 13 \\
\hline 6 & 5 & 6 & 3 & 5 & 11 \\
\hline 7 & 4 & 5 & 3 & 4 & 9 \\
\hline 8 & 3 & 4 & 2 & 3 & 8 \\
\hline 16 & 2 & 3 & 2 & 2 & 6 \\
\hline 23 & 2 & 3 & 2 & 2 & 6 \\
\hline 87 & 2 & 3 & 2 & 2 & 4 \\
\hline 93 & 2 & 3 & 2 & 2 & 4 \\
\hline 111 & 2 & 3 & 2 & 2 & 4 \\
\hline 120 & 2 & 3 & 2 & 2 & 4 \\
\hline
\end{tabular}


Table 5 shows the results of the thermal stability of chicken feet, pork, and beef gelatines at a temperature of $29{ }^{\circ} \mathrm{C}$ and humidity of $80 \%$.

At this humidity, a slightly higher decline of gel strength was monitored in commercial gelatines than at the humidity of $60 \%$; while in chicken feet gelatine no statistically significant differences $(p>0.05)$ were recorded, similarly as at the temperature of $23{ }^{\circ} \mathrm{C}$. After $1 \mathrm{~h}$ of measurement, the smallest decline was recorded in Beef266, slightly higher in pork gelatines and the deepest decrease in Beef273 a CFG240. In contrast, after $2 \mathrm{~h}$ of measurement, the smallest drop of approximately $70 \%$ was in CFG240, slightly deeper in Beef266 and Pork288, and the most significant reduction of approximately $80 \%$ in Beef273. After $3 \mathrm{~h}$, the last drop was in CFG240, similarly to further measurements, while commercial gelatines performed slightly deeper reduction of gel strength. Further measurements showed a trend of a gradual decline of gel strength; importantly, commercial gelatines performed statistically significant $(p<0.05)$ higher decrease of gel strength if compared with chicken feet gelatine. After $87 \mathrm{~h}$, almost $100 \%$ declines in gel strength in all gelatines were monitored. It has been proved that chicken gelatine performs comparable or even better properties than commercial gelatines considering the thermal stability of gelatine gel strength.

Table 6 summarizes the results of the thermal stability of chicken feet, pork, and beef gelatines at the temperature of $35{ }^{\circ} \mathrm{C}$ and humidity of $60 \%$. All gelatines performed a steep decline of gelatine gel strength at this temperature. After $1 \mathrm{~h}$ of measurement, the decrease ranged between 38 and $43 \%$ with the smallest drop in CFG240 and the highest in Beef266 and Pork212. A dramatic decline of gel strength from 83 to $90 \%$ was recorded in further measurements. The smallest reduction was determined in Beef266 and the highest in Beef273. After $3 \mathrm{~h}$ of measurement, the smallest decline of more than $90 \%$ was in CFG240 while all commercial gelatines showed at a drop of $97 \%$. After $4 \mathrm{~h}$, almost all gelatines performed a decrease of nearly $100 \%$ and no gelatine formed a gel after $5 \mathrm{~h}$ of measurement.
The results of the thermal stability of chicken feet, pork, and beef gelatines at the temperature of $35{ }^{\circ} \mathrm{C}$ and humidity of $80 \%$ are shown in Table 7 . The figures do not differ much from the results at the same temperature at the humidity of $60 \%$. After $1 \mathrm{~h}$ of measurement, the decline of gel strength varied from 36 to $42 \%$ which proves no statistically significant differences $(p>0.05)$ between the experiments at the humidity of 80 and $60 \%$. The smallest decrease of gel strength was established in CFG240 and Pork288 while the deepest drop was recorded in Beef266, equally as at the humidity of $60 \%$. After $2 \mathrm{~h}$ of measurement, chicken feet gelatine showed the smallest decline $(75 \%)$, and Pork212 together with other beef gelatines the biggest fall (85\%). After $3 \mathrm{~h}, \mathrm{CFG} 240$ performed a decline of gel strength of more than $91 \%$ and commercial gelatines of $97 \%$. Nearly $100 \%$ decline of gel strength in all gelatines was recorded after $4 \mathrm{~h}$ of measurement. Equally, as in previous experiments, comparable declines of gelatine gel strength were recorded in both chicken feet and commercial gelatines at the temperature of $35^{\circ} \mathrm{C}$.

\section{CONCLUSION}

Chicken feet gelatine (CFG) was obtained from chicken feet, a slaughterhouse by-product, using a biotechnological method with a previous proteolytic enzyme pre-treatment and extracted at the temperature of $80{ }^{\circ} \mathrm{C}$ for $45 \mathrm{~min}$. Samples of gels were prepared both from CFG and commercial pork and beef gelatine and their thermal stability were tested. For the experiments, the thermal stability of gelatine gels was defined as a percentage change of gel strength in time and it was recorded at temperatures of 23,29 , and $35^{\circ} \mathrm{C}$ at the relative humidity of 60 and $80 \%$ for 5 days. These temperatures and humidities were proposed to reflect the climatic conditions common during the storage of products containing gelatine gel in the summer or tropical areas. The results have shown that the thermal stability of gelatine gels is lower at higher storage temperatures confirming the hypothesis. However, the assumption that higher humidity will cause a steeper decline in gel strength has not been proved.

Table 6 Thermal stability of chicken feet, beef and pork gelatines at $35{ }^{\circ} \mathrm{C}$ and relative humidity of $60 \%$.

\begin{tabular}{cccccc}
\hline Temperature of $35{ }^{\circ} \mathbf{C}$; relative humidity of $\mathbf{6 0} \%$ & \multicolumn{4}{c}{ Type of gelatine/Bloom index $(\%)$} \\
\hline Time of measurement $(\mathbf{h})$ & Beef266 & Beef273 & Pork212 & Pork288 & CFG240 \\
\hline 0 & 100 & 100 & 100 & 100 & 100 \\
1 & 57 & 58 & 57 & 61 & 62 \\
2 & 17 & 11 & 15 & 12 & 15 \\
3 & 3 & 3 & 3 & 3 & 7 \\
4 & 2 & 2 & 1 & 2 & 0 \\
5 & 0 & 0 & 0 & 0 \\
\hline
\end{tabular}

Table 7 Thermal stability of chicken feet, beef and pork gelatines at $35^{\circ} \mathrm{C}$ and relative humidity of $80 \%$.

\begin{tabular}{cccccc}
\hline Temperature of $35{ }^{\circ} \mathbf{C}$; relative humidity of $\mathbf{8 0} \%$ & \multicolumn{4}{c}{ Type of gelatine/Bloom index (\%) } \\
\hline Time of measurement $(\mathbf{h})$ & Beef266 & Beef273 & Pork212 & Pork288 & CFG240 \\
\hline 0 & 100 & 100 & 100 & 100 & 100 \\
1 & 58 & 60 & 60 & 64 & 64 \\
2 & 15 & 15 & 15 & 19 & 25 \\
3 & 3 & 3 & 3 & 3 & 2 \\
4 & 2 & 2 & 2 & 0 & 0 \\
\hline 5 & 0 & 0 & 0 & 0 & 3 \\
\hline
\end{tabular}


The thermal stability of prepared chicken feet gelatine has not been significantly affected by humidity. On the other hand, the results of commercial gelatines at different humidities were not definite.

This fact favours the applications of chicken gelatine in the food industry; the thermal stability of chicken gelatine was higher or similar to the stability of commercial mammalian gelatines. Experiments at a temperature of 23 ${ }^{\circ} \mathrm{C}$ showed that the highest thermal stability was recorded in chicken gelatine at the humidity of both 60 and $80 \%$. The decline of the strength of chicken feet gelatine gel was in earlier times of measurement approximately $1.5 \mathrm{x}$ lower and in later times of measurements even nearly as $2 \mathrm{x}$ lower than in commercial gelatines. At the temperature of $29^{\circ} \mathrm{C}$, comparable results in both commercial and chicken feet gelatines were established. The last tested temperature was $35{ }^{\circ} \mathrm{C}$ also providing a similar decline of the strength in chicken feet gelatine gels and commercial gelatines. This study has confirmed that laboratory prepared chicken feet gelatine provides similar thermal stability to gels of commercial pork and beef gelatine. Hence chicken feet gelatine may be employed as a potential alternative to traditional gelatines used in the food industry in the production of confections, aspics, or desserts. This data clarifying the behavior of gelatine gels thermal stability is beneficial also for further industrial sectors, such as for the preparation of hard gelatine capsules in the pharmaceutical industry.

\section{REFERENCES}

Almeida, P. F., Lannes, S. C. S. 2013. Extraction and Physicochemical Characterization of Gelatin from Chicken By-Product, Journal of Food Processing, vol. 36, no. 6. p. 824. https://doi.org/10.1111/jfpe.12051

Almeida, P. F. D., Calarge, F. A., Santana, J. C. C. 2013. Production of a Product Similar to Gelatine from Chicken Feet Collagen. Engenharia Agrícola, vol. 33, no. 6, p. 1289-1300. 69162013000600021

Asghar, A., Henrickson, R. L. 1982. Chemical, Biochemical, Functional, and Nutritional Characteristics of Collagen in Food Systems. Advances in Food Research, vol. 28, p. 231-372. https://doi.org/10.1016/S00652628(08)60113-5

Bae, I., Osatomi, K., Yoshida, A., Osako, K., Yamaguchi, A., Hara, K. 2008. Biochemical Properties of Acid-Soluble Collagens Extracted from the Skins of Underutilised Fishes. Food Chemistry, vol. 108, no. 1, p. 49-54. https://doi.org/10.1016/j.foodchem.2007.10.039

Bogue, R. H. 1922. The Chemistry and Technology of Gelatin and Glue. London : McGraw-Hill book co., 644 p. ISBN-13 978-1331666585.

Bigi, A., Panzavolta, S., Rubini, K. 2004. Relationship between Triple-Helix Content and Mechanical Properties of Gelatin Films. Biomaterials, vol. 25 no. 25, p. 56755680. https://doi.org/10.1016/j.biomaterials.2004.01.033

Canpanean, V., Gabudean, A. M., Astilean, S. 2013. Enhanced Thermal Stability of Gelatin Coated Gold Nanorods in Water Solution. Colloids and Surfaces A: Physicochemical and Engineering Aspects, vol. 433, no. 2013, p. 9-13.
Chakka, A., Muhammed, A., Sakhare, P. Z., Bhaskar, N. 2016. Poultry Processing Waste as an Alternative Source for Mammalian Gelatin, Waste and Biomass Valorization, vol. 8, no. $8, \quad$ p. 2583-2593. https://doi.org/10.1007/s12649-016-9756-1

Deyl, Z., Mikšík, I., Eckhardt, A. 2003. Preparative Procedures and Purity Assessment of Collagen Proteins. Journal of Chromatography B, vol. 790, no. 1, p. 245-275. https://doi.org/10.1016/S1570-0232(03)00158-2

Du, L., Keplová, L., Khiari, Z., Betti, M. 2014. Preparation and Characterization of Gelatine from Collagen Biomass Obtained Through a pH-shifting Process of Mechanically Separated Turkey Meat. Poultry Science, vol. 93, no. 4, p. 989-1000. https://doi.org/10.3382/ps.2013-03609

Ee, S., Saari, N., Abas, F., Ismail, A., Bakar, M., Bakar, J. 2019. Properties of Chicken Head Gelatins as Affected by Extraction Method. International Food Research Journal, vol. 26, no. 2, p. 499-508. Available at: http://psasir.upm.edu.my/id/eprint/68872/.

Fonkwe, L. G., Singh, R. K. 1997. Production and Characterization of Gelatinous Protein Extracts from Turkey Deboner Residue. Process Biochemistry, vol. 32, no. 4 , p. 309-318. https://doi.org/10.1016/S00329592(96)00087-8

Gómez-Guillén, M., Giménez, B., López-Caballero, M., Montero, M. 2011. Functional and Bioactive Properties of Collagen and Gelatin from Alternative Sources: A Review. Food Hydrocolloids, vol. 25, no. 8, p. 1813-1827. https://doi.org/10.1016/j.foodhyd.2011.02.007

Gelatin Market Analysis 2019-2025. Reuters. Available at: https://www.reuters.com/brandfeatures/venturecapital/article?id=87818.

GMIA - Standard Testing Methods for Edible Gelatin. 2019. Available at: http://www.gelatingmia.com/uploads/1/1/8/4/118450438/gmia_official_meth ods_2019.pdf.

Grand View Research. 2020. Gelatin Market Size, Share \& Trends Analysis Report by Raw Material (Pig Skin, Cattle Bones), by Function (Stabilizer, Gelling Agent), By Application (Photography, Food \& Beverage), and Segment Forecasts, 2019 - 2025. 300 P. Report Id: 978-1-68038-1108.

Holzer, D. 1996 - Gelatine Production, US Patent 5, 484, 888.

Jellouli, K., Balti, R., Bougatef, A., Hmidet, N., Barkia, A., Nasri, M. 2011. Chemical Composition and Characteristics of Skin Gelatin from Grey Triggerfish (Balistes capriscus). LWT - Food Science and Technology, vol. 44, no. 9, p. 1965-1970. https://doi.org/10.1016/j.lwt.2011.05.005

Johnston-Bank, F. A. 1983. From Tannery to Table: an Account of Gelatin Production. Journal of the Society of Leather Technologists and Chemists, vol. 68, p. 141-145.

Koepff, P. 1985. History of Industrial Gelatin Production. In H. Amman-Brass \& J. Pouradier (Eds.), Photographic gelatin, proceedings of the fourth IAG conference. Fribourg, Switzerland: Internationale Arbeitsgemeinschaft fur photogelatin, p. 3-31.

Krishnamoorthi, J., Ramasamy, P., Shanmugam, V., Shanmugam, A. 2017. Isolation And Partial Characterization of Collagen from Outer Skin of Sepia Pharaonis (Ehrenberg, 1831) from Puducherry coast. 
Biochemistry and Biophysics, vol. 10, p. 39-45. https://doi.org/10.1016/j.bbrep.2017.02.006

Li, F. Jia, D. Yao, K. 2009. Amino Acid Composition and Functional Properties of Collagen Polypeptide from Yak (Bos Grunniens) Bone. LWT-Food Science and Technology, vol. 42, no. 5, p. 945-949. https://doi.org/10.1016/j.lwt.2008.12.005

Losso, J. N., Ogawa, M. 2013. Thermal Stability of Chicken Keel Bone Collagen. Journal of Food Biochemistry, vol. 38, no. 3, p. 345351. https://doi.org/10.1111/jfbc.12059

Maroušek, J., Maroušková, A., Myšková, K., Váchal, J., Vochozka, M., Žák, J. 2015. Techno-Economic Assessment of Collagen Casings Waste Management. International Journal of Environmental Science and Technology, vol. 12, no. 10, p. 3385-3390. Available at: https://link.springer.com/article/10.1007\%2Fs13762-0150840-z.

Masutani, E. M., Kinoshita, C. K., Tanaka, T. T., Ellison, A. K. D., Yoza, B. A. 2014. Increasing Thermal Stability of Gelatin by UV-Induced Cross-Linking with Glucose. International Journal of Biomaterials, vol. 2014, p. 9. https://doi.org/10.1155/2014/979636

Michon, C., Cuvelier, G., Relkin, P., Launay, B. 1997. Influenece of Thermal History on the Stability of Gelatin Gels. International Journal of Biological Macromolecules, vol. 20, no. 1997, p. 259-264. https://doi.org/10.1016/S0141-8130(97)00024-X

Mohtar, N. F., Perera, C. O., Quek, S. Y. 2010. Optimisation of Gelatine Extraction from Hoki (Macruronus Novaezelandiae) Skins and Measurement of Gel Strength and SDS-PAGE. Food Chemistry, vol. 122, no. $1, \quad$ p. 307-313. https://doi.org/10.1016/j.foodchem.2010.02.027

Mokrejš, P., Mrázek, P., Gál, R., Pavlačková, J. 2019. Biotechnological Preparation of Gelatines from Chicken Feet. Polymers, vol. 11, no. 6, p. 1060. https://doi.org/10.3390/polym11061060

Mrázek, P., Mokrejš, P., Gál, R., Orsavová, J. 2019. Chicken Skin Gelatine as an Alternative to Pork and Beef Gelatines. Potravinarstvo Slovak Journal of Food Sciences, vol. 13, no. 1, p. 224-233. https://doi.org/10.5219/1022

Pati, F., Adhikari, B., Dhara, S. 2010. Isolation and Characterization of Fish Scale Collagen of Higher Thermal Stability, Bioresource Technology, vol. 101, no. 2010, p. 3737-3742. https://doi.org/10.1016/j.biortech.2009.12.133

Perez-Tamayo, R. 1978. Pathology of Collagen Degradation. American Journal of Pathology, vol. 92, no. 2, p. 509-566.

Rafieian, F., Keramat, J., Kadivar, M. 2013. Optimization of Gelatin Extraction from Chicken Deboner Residue Using RSM Method. Journal of Food Science and Technology, vol. 50, no. 2, p. 374-380. https://doi.org/10.1007/s13197-011-0355-7

Rafieian, F., Keramat, J., Shahedi, M. 2015. Physicochemical Properties of Gelatin Extracted from Chicken Deboner Residue. LWT - Food Science and Technology, vol. 64, no. 2, p. 1370-1375. https://doi.org/10.1016/j.lwt.2015.04.050

Rahman, M., N., A., Jamalulail, S. A. S. K. A. 2012. Extraction, Physicochemical Characterizations and
Sensory Quality of Chicken Feet Gelatin, Borneo Science, vol. 30. Available at: http://eprints.ums.edu.my/12414/.

Rodriguez-Castellanos, W., Flores-Ruiz, F. J., MartinezBustos, F. Chinas-Castillo, F., Espinoza-Beltran, F. J.

2014. Nanomehcanical Properties and Thermal Stability of Recycled Cellulose reinforced Starch-gelatin Polymer Composite. Journal of Applied Polymer Science, vol. 132, no. 14, p. 1-7. https://doi.org/10.1002/app.41787

Rodriguez-Rodriguez, R., Garcia-Carvajal, Z. Y., Jimenez-Palomar, I., Jimenez-Avalos, J. A., EspinozaAndrews, H. 2019. Development of Gelatin/Chitosan/PVA hydrogels: Thermal Stability, Water State, Viscoelasticity, and Cytotoxicity Assays. Journal of Applied Polymer Science, vol. 136, no. 6, p. $1-9$. https://doi.org/10.1002/app.47149

Sarbon, N. M., Badii, F., Howell, N. K. 2013. Preparation and Characterisation of Chicken Skin Gelatin as an Alternative to Mammalian Gelatin. Food Hydrocolloids, vol. 30, no. 1, p. 143-151. https://doi.org/10.1016/j.foodhyd.2012.05.009

Schrieber, R., Gareis, H. 2007. Gelatin Handbook. Theory and Industrial Practice, Wiley-VCH Verlag GmbH \& Co. KGaA. Weinheim, Germany, 347 p. ISBN 9783527610969.

Silvipriya, K. S., Krishna Kumar, K., Bhat, A. R., Dinesh Kumar, B., John, A., Lakshmanan, P. 2015. Collagen: Animal Sources and Biomedical Application. Journal of Applied Pharmaceutical Science, vol. 5, no. 3, p. 123-127. https://doi.org/10.7324/JAPS.2015.50322

Smith, P. I. 1929. Glue and gelatin. London: Pitman Press, $162 \mathrm{p}$.

Sompie, M., Triasih, A. 2018. Effect of Extraction Temperature on Characteristics of Chicken Legskin. In Proceedings of IOP Conference Series: Earth and Environmental Science 2017 [Online] Semarang, Indonesia, 26-27 September, p. 12089.

Subhan, F., Kang, H. Y., Lim, Y., Ikram, M., Baek, S. Y., Jin, S., Jeong, Y. H., Kwak, J. Y., Yoon, S. 2017. Fish Scale Collagen Peptides Protect Against Cocl2/TNF- AInduced Cytotoxicity and Inflammation via Inhibition Of ROS, MAPK, and NF-K B Pathways. HaCat Cells. Oxidative Medicine and Cellular Longevity, vol. 2017, no. 1, p. 1-17. https://doi.org/10.1155/2017/9703609

Taufik, M., Triatmojo, S., Erwanto, J., Santoso, U. 2010. Effect of Broiler Age and extraction Temperature on Characteristic Chicken Feet Skin Gelatine, The $5^{\text {th }}$ International Seminar on Tropical Animal Production, Community Empowerement and Tropical Animal Industry. Yogyakarta, Indonesia.

Widyasari, R., Rawdkuen, S. 2014. Extraction and Characterization of Gelatin from Chicken Feet by Acid and Ultrasound Assisted Extraction, Food Applied Bioscience Journal, vol. 2, no. 1, p. 85-97. https://doi.org/10.14456/fabj.2014.7

\section{Acknowledgments:}

This research was financially supported by the Internal Grant Agency of the Faculty of Technology, Tomas Bata University in Zlín, ref. IGA/FT/2020/002. 


\section{Contact addresses:}

*Petr Mrázek, Tomas Bata University in Zlín, Faculty of technology, Department of Polymer Engineering, Vavrečkova 275, 760 01, Zlín, Czech Republic, Tel.: +420576031331,

E-mail: p_mrazek@utb.cz

ORCID: https://orcid.org/0000-0002-5436-5019

Robert Gál, Tomas Bata University in Zlín, Faculty of technology, Department of Food Technology, Vavrečkova 275, 76001 Zlín, Czech Republic, Tel.: +420 576033 006, E-mail: gal@utb.cz

ORCID: https://orcid.org/0000-0001-6110-7918

Pavel Mokrejš, Tomas Bata University in Zlín, Faculty of technology, Department of Polymer Engineering, Vavrečkova 275, 760 01, Zlín, Czech Republic, Tel.: +420 576031230 ,

E-mail: mokrejs@utb.cz

ORCID: https://orcid.org/0000-0002-3168-413X
Ondřej Krejčí, Tomas Bata University in Zlín, Faculty of technology, Department of Polymer Engineering, Vavrečkova 275, 760 01, Zlín, Czech Republic, Tel.: +420 576031230 ,

E-mail: okrejci@utb.cz

ORCID: https://orcid.org/0000-0002-2683-5271

Jana Orsavová, Tomas Bata University in Zlín, Faculty of humanities, Language Centre, Štefánikova 5670, 76001 Zlín, Czech Republic, Tel.: +420 576038 158,

E-mail: orsavova@utb.cz

ORCID: https://orcid.org/0000-0001-9766-6033

*Corresponding author 